\title{
Pengaruh Brand Image Terhadap Keputusan Memilih Bimbingan Belajar Pada Lembaga Pendidikan Ganesha Operation Di Pekanbaru
}

\author{
DWIKA LODIA PUTRI, AZNURIYANDI
}

\author{
Universitas Lancang Kuning \\ Jln. Yos Sudarso Km 08 Rumbai Telp. (0761) 52581 Fax. (0761) 52581 \\ E-mail : lodiaputri_62@yahoo.com
}

\begin{abstract}
The purpose of this research is to know the influence of Brand Image against the decision of choosing a tutoring on Ganesha Institution in Pekanbaru. This research was conducted on students tutoring Ganesha Operation in Pekanbaru. Method of data collection in this research is the use of a detailed questionnaire and filed research consisting of observasi and interviews. The population in this study is taken from the number of students as much as 71 people respondents. Methods analyst data used in this study is a simple linear regression method of tabulate data from likert scale with the use of a detailed questinnaire. The results from this research that the brand image of a significant effect against the decision of choosing atutoring on Ganesha Operation, with the purchasing decisions of $89,50 \%$ variable is determined by the brand iamge while the rest of $10,50 \%$ determined by other variables outside of research.
\end{abstract}

Keywords: Brand Image, Purchasing Decisions

Seiring dengan perkembangan perekonomian, ilmu, dan teknologi yang terjadi di Indomesia, membawa dampak persaingan bagi kehidupan manusia di bidang usaha, baik transportasi, makanan serta minuman, maupun bidang pendidikan. Kondisi persaingan di bidang pendidikan mulai dirasakan oleh setiap sekolah khususnya sekolah menengah pertama (SMP) dan sekolah menengah atas (SMA). Berbeda dengan zaman dahulu, dimana orang tua menyekolahkan anaknya di sekolah yang dekat dengan rumah, tetapi seiring dengan perkembangan zaman pihak orang tua menginginkan anaknya bersekolah di tempat yang memiliki kredibilitas dan cara pengajaran yang memiliki mutu baik.

Salah satu Bimbingan Belajar yang keberadaannya sudah dikenal secara luas adalah Ganesha Operation (GO). Ganesha Operation telah menjadi bagian dari sejarah kehidupan masyarakat Indonesia sejak 1984. Sejak saat ini, Ganesha

Operation terus mengembangkan dan membuktikan diri sebagai Bimbingan Belajar terbaik dan terbesar di Indonesia. Bimbingan belajar Ganesha Operation tersebar diberbagai daerah di Indonesia salah satunya di kota Pekanbaru.

Merek merupakan sebuah nama, istilah, tanda, lambang, atau desain, atau kombinasi semua ini, yang menunjukkan identitas pembuat atau penjual produk atau jasa (Kotler, Philip dan Amstrong, 2008:275). Merek bukan hanya sebuah nama, simbol, gambar atau tanda yang tidak berarti melainkan merek merupakan identitas sebuah produk yang dapat dijadikan sebagai alat ukur apakah produk itu baik dan berkualitas yang dapat mengidentifikasi barang atau jasa dari seseorang atau sekelompok penyaji dan membedakannya dari produk sejenis dari penyaji lain dan jika perusahaan mampu membangun merek yang kuat dipikiran pelanggan melalui strategi pemasaran yang tepat, perusahaan akan mampu membangun mereknya.

Perusahaan harus memiliki merek yang berbeda dengan pesaingnya, begitu pula dengan citra merek yang tertanam di benak pelanggan. Karena citra merek merupakan salah satu hal yang dilihat pertama kali oleh pelanggan sebelum 
melakukan pembelian atau pemilihan produk.

Menurut Kotler dan Keller (2012:248) "Brand Imagery drscribes the extrinsic properties of the product or service, including the ways in which the brand attempts to meet customers psychological or social needs" Brand Image menggambarkan sifat ekstrinsik dari suatu produk atau jasa termasuk cara dimana merek berusaha memenuhi kebutuhan psikologis atau sosial pelanggan.

Faktor-faktor yang menjadi pendukung brand image menurut Aris (2009:196) adalah: a. Product Attributes. Sebuah brand dapat memunculkan sejumlah atribut produk tertentu dalam pikiran pelanggan,yangmengingatkannya pada karekteristik brand tersebut. b. Consumer Benefits, Sebuah brand harus bisa memberikan suatu value tersendiri bagi konsistensinya yang akan dilihat oleh pelanggan sebagai benefits yang diperolehnya ketika ia membeli atau mengkonsumsi produk tersebut.

Menurut Kotler dan Keller (2012: 166), "Buying decision is process all the experiences in learning, choosing, using, and event disposing of a product" Yang berarti bahwa keputusan pembelian adalah semua pengalaman dalam pembelajaran,pemilihan,penggunaan,dan bahkanmenyingkirkan produk.

Keputusan pembelian menurut Alma (2011:96) adalah suatu keputusan konsumen yang dipengaruhi oleh ekonomi keuangan, teknologi, politik, budaya, produk, harga, lokasi, promosi, physical evidence, people dan process, sehingga membentuk suatu sikap pada konsumen untuk mengolah segala informasi dan mengambil kesimpulan berupa respon yang muncul, produk apa yang akan dibeli.

Perilaku konsumen merupakan tindakan yang langsung terlibat dalam mendapatkan, mengkonsumsi dan menghabiskan produk dan jasa termasuk proses keputusan yang mendahului dan menyusuli tindakan ini. Beberapa pendapat dari para ahli tentang definisi perilaku konsumen, yaitu: Kotler dan Amstrong (2014: 279) mengatakan perilaku konsumen sebagai perilaku pembelian konsumen akhir, baik individu maupun rumah tangga, yang membeli produk untuk konsumsi personal. Perilaku konsumen merupakan interaksi dinamis antara efeksi (perasaan) dan kognisi (pikiran), perilaku dan lingkungannya dimana manusia melakukan kegiatan pertukaran dalam hidup mereka.

Model penelitian ini dapat digambarkan sebagai berikut:

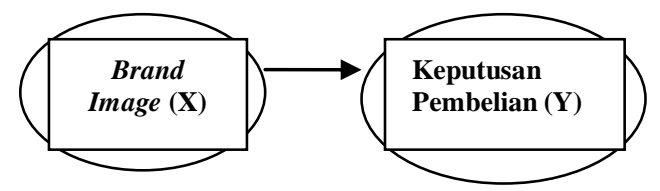

Independen

Dependen

\section{METODE}

Jenis data yang digunakan dalam penelitian ini adalah: 1. Data Primer adalah data yang memberikan data langsung kepada pengumpul data (Sugiyono, 2013:193). Untuk mendapatkan data primer peneliti mengumpulkan data secara langsung dengan membagikan kuesioner kepada responden. 2. Data Sekunder sumber data yang didapat melalui orang lain atau dokumen. Data sekunder diperoleh dari berbagai sumber seperti buku, laporan, jurnal internet serta sumber lain yang berkaitan dengan objek penelitian.

Teknik pengumpulan data yang dipakai dalam penelitian ini terdiri dari: 1.Observasi yaitu metode pengumpulan data yang dilakukan dengan cara mengadakan pengamatan langsung pada objek penelitian dan melakukan pencatatam sehubungan dengan masalah yang diteliti. 2.Wawancara yaitu metode pengumpulan data dengan cara tanya jawab langsung dengan beberapa siswa mengenai masalah yang akan diteliti. 3.Kuesioner adalah metode pengumpulan data dengan menggunakan daftar pertanyaan yang disebarkan kepada responden.

Populasi dalam penelitian ini adalah seluruh siswa yang kursus pada Lembaga 
Pendidikan Ganesha di Kota Pekanbaru sebanyan 351 orang tahun 2017 - 2018. Sampel diambil dengan menggunakan rumus Solvin sebagai berikut:

$$
\begin{aligned}
\mathrm{N}= & \frac{\mathrm{N}}{1+\mathrm{N} \cdot \mathrm{e}^{2}} \\
\mathrm{~N} & =\frac{351}{1+351}(0,1)^{2} \\
& =71,20=71
\end{aligned}
$$

Keterangan :

$\mathrm{n}$ = Ukuran sampel

$\mathrm{N}=$ Ukuran populasi

$\mathrm{D}=$ Persentase kelonggaran ketidak telitian yang dapat ditolerir 10\%

Teknik pengambilan sampel dengan Stratified Random Sampling yaitu teknik pengambilan sampel yang apabila populasi mempunyai anggota atau unsur heterogen dan bersrata proposional (Sugiyono, 2013:195). Adapun rumus dari Proportionate stratified random sampling, yaitu sebagai berikut $\mathrm{n}=$ (Populasi Kelas/Jumlah Populasi Keseluruhan x Jumlah Sampel).

\section{HASIL}

Penelitian ini dilakukan pada 71 orang peserta kursus di Lembaga Pendidikan Ganesha Operation Pekanbaru. Bertujuan untuk mengetahui pengaruh Brand Image terhadap keputusan memilih bimbingan belajar pada Lembaga Pendidikan Ganesha Operation Pekanbaru.

a. Hasil Uji Validitas

Hasil Uji Validitas

\begin{tabular}{|l|l|l|l|l|}
\hline $\begin{array}{l}\text { Variab } \\
\text { el }\end{array}$ & $\begin{array}{l}\text { Pernyat } \\
\text { aan }\end{array}$ & $\begin{array}{l}\mathrm{r} \\
\text { Hitung }\end{array}$ & Signifikansi & $\begin{array}{l}\text { Keterang } \\
\text { an }\end{array}$ \\
\hline Brand & 1 & 0,594 & 0,000 & Valid \\
Image & 2 & 0,489 & 0,000 & Valid \\
$\left(\mathrm{X}_{1}\right)$ & 3 & 0,574 & 0,000 & Valid \\
& 4 & 0,416 & 0,000 & Valid \\
& 5 & 0,344 & 0,000 & Valid \\
& 6 & 0,429 & 0,000 & Valid \\
& 7 & 0,546 & 0,000 & Valid \\
& 8 & 0,528 & 0,000 & Valid \\
& 9 & 0,274 & 0,000 & Valid \\
& 10 & 0,518 & 0,000 & Valid \\
& 11 & 0,292 & 0,000 & Valid \\
& 12 & 0,288 & 0,000 & Valid \\
& 13 & 0,443 & 0,000 & Valid \\
& 14 & 0,618 & 0,000 & Valid \\
& 15 & 0,327 & 0,000 & Valid \\
& 16 & 0,359 & 0,000 & Valid \\
& 17 & 0,547 & 0,000 & Valid \\
& 18 & 0,556 & 0,000 & Valid \\
& 19 & 0,334 & 0,000 & Valid \\
\hline
\end{tabular}

\begin{tabular}{|l|l|l|l|l|}
\hline & 20 & 0,477 & 0,000 & Valid \\
\hline Keputu & 1 & 0,579 & 0,000 & Valid \\
san & 2 & 0,651 & 0,000 & Valid \\
Pembel & 3 & 0,356 & 0,000 & Valid \\
ian (Y) & 4 & 0,288 & 0,000 & Valid \\
& 5 & 0,363 & 0,000 & Valid \\
& 6 & 0,490 & 0,000 & Valid \\
& 7 & 0,441 & 0,000 & Valid \\
& 8 & 0,419 & 0,000 & Valid \\
& 9 & 0,346 & 0,000 & Valid \\
& 10 & 0,361 & 0,000 & Valid \\
& 11 & 0,426 & 0,000 & Valid \\
& 12 & 0,333 & 0,000 & Valid \\
& 13 & 0,400 & 0,000 & Valid \\
& 14 & 0,571 & 0,000 & Valid \\
& 15 & 0,561 & 0,000 & Valid \\
& 16 & 0,533 & 0,000 & Valid \\
& 17 & 0,414 & 0,000 & Valid \\
& 18 & 0,406 & 0,000 & Valid \\
& 19 & 0,315 & 0,000 & Valid \\
& 20 & 0,412 & 0,000 & Valid \\
\hline
\end{tabular}

Sumber: Hasil Pengolahan Data, 2019

b. Hasil Uji Reliabilitas

Hasil Uji Reliabilitas

\begin{tabular}{|l|l|l|}
\hline $\begin{array}{l}\text { Sub } \\
\text { Variabel }\end{array}$ & $\begin{array}{l}\text { Alpha } \\
\text { Cronbach's }\end{array}$ & Keterangan \\
\hline $\begin{array}{l}\text { Brand } \\
\text { Image }\left(\mathrm{X}_{1}\right)\end{array}$ & 0,781 & Reliabel \\
\hline $\begin{array}{l}\text { Keputusan } \\
\text { Pembelian } \\
(\mathrm{Y})\end{array}$ & 0,786 & Reliabel \\
\hline
\end{tabular}

Sumber: Hasil Pengolahan Data, 2019

Dari tabel diatas terlihat nilai Alpha Cronbach's diatas 0,71, ini berarti bahwa tingkat kehandalan dari butir-butir pertanyaan untuk variabel yang diteliti sudah reliabel. Dengan demikian semua butir untuk kedua variabel sudah baik.

\section{Hasil Uji Normalitas}

Pengujian normalitas dilakukan dengan uji one sampel kolmogorov-smirnov. Hasil pengujian normalitas dapat dilihat dalam tabel di bawah ini:

Hasil Uji Normalitas Data

\begin{tabular}{|l|l|l|l|}
\hline Variabel & $\begin{array}{l}\text { Asym.Sig } \\
\text { (2- Tailed) }\end{array}$ & Alpha & Keterangan \\
\hline $\begin{array}{l}\text { Keputusan dan } \\
\text { pembelian } \\
\text { BrandImage }\end{array}$ & 0,849 & 0,050 & Normal \\
\hline
\end{tabular}

Sumber: Hasil Pengolahan Data,2019

Dari tabel dapat dilihat nilai asyim.sig (2-tailed) untuk kedua variabel penelitian yaitu keputusan pembelian dan promosi memiliki nilai yang lebih besar dari alpha. 
Dengan demikian dikatakan bahwa data untuk kedua variabel yang diteliti sudah berdistribusi normal atau asumsi dalam regresi linear sederhana sudah terpenuhi.

\section{Hasil Uji Hipotesis}

$$
\mathrm{Y}=29,380+0,654 \mathrm{X}
$$

Artinya:

1. Nilai konstanta (a) adalah bernilai positif sebesar 29,380 artinya jika Brand Image nilainya 0 (Nol) maka keputusan pembelian tetap sebesar 29,380 .

2. Nilai koefisien regresi variabel Brand Image (X) bernilai positif sebesar 0, 654 artinya setiap peningkatan variabel Brand Image (X) sebesar 1 satuan maka akan meningkatkan keputusan pembelian sebesar 0,654 satuan dengan asumsi variabel lain bernilai tetap.

Hasil Uji Secara Parsial (Uji t)

\begin{tabular}{|l|l|l|l|l|l|}
\hline $\begin{array}{l}\mathrm{N} \\
\mathrm{O}\end{array}$ & $\begin{array}{l}\text { Variabe } \\
1\end{array}$ & $\begin{array}{l}\mathrm{t} \\
\text { Hitun } \\
\mathrm{g}\end{array}$ & $\begin{array}{l}\text { Signifika } \\
\mathrm{n}\end{array}$ & $\begin{array}{l}\alpha= \\
5 \%\end{array}$ & Keterangan \\
\hline 1 & $\begin{array}{l}\text { Brand } \\
\text { Image }\end{array}$ & 3,678 & 0,000 & $\begin{array}{l}0,07 \\
1\end{array}$ & $\begin{array}{l}\text { Berpengaru } \\
\mathrm{h} \\
\text { Signifikan }\end{array}$ \\
\hline
\end{tabular}

Sumber: Hasil Olahan 2019

Berdasarkan tabel diatas diperoleh signifikan $\mathrm{t}$ hitung variabel Brand Image lebih kecil alpha $(\alpha) 5 \%$ yaitu $0,005<0,05$ yang berarti Brand Image berpengaruh terhadap keputusan pembelian.

Koefisien Korelasi (R) dan Koefisien Determinasi $\left(\mathrm{R}^{2}\right)$

Model Summary ${ }^{\mathrm{b}}$

\begin{tabular}{|l|l|l|l|l|}
\hline $\begin{array}{l}\text { Mode } \\
1\end{array}$ & $\mathrm{R}$ & $\mathrm{R}$ Square & $\begin{array}{l}\text { Adjusted } \\
\text { Square }\end{array}$ & $\begin{array}{l}\text { Std. Error of } \\
\text { the Estimate }\end{array}$ \\
\hline 1 & $.946^{\mathrm{a}}$ & .895 & .892 & 3.892 \\
\hline
\end{tabular}

a. Predictors: (Constant), Brand Image

b. Dependent Variable: Keputusan Pembelian

Sumber: Hasil Olahan SPSS. 2019

Dari tabel diatas dapat dilihat koefisien korelasi (R) diperoleh sebesar 0,946 hal ini memberikan arti bahwa antara variabel
Brand Image dan Keputusan pembelian terdapat hubungan yang sangat kuat, dimana variasi keputusan pembelian sebesar $89,50 \%$ ditentukan oleh variabel Brand Image sedangkan sisanya sebesar $10,50 \%$ ditentukan oleh variabel lain yang tidak diteliti.

\section{PEMBAHASAN}

Penelitian ini bermaksud untuk mengetahui pengaruh Brand Image terhadap keputusan memilih bimbingan belajar pada Lembaga Pendidikan Ganesha Operation Pekanbaru. Yang mana di indikasikan citra merek (brand image) dapat menjadi salah satu faktor yang dapat mempengaruhi keputusan memilih bimbingan belajar pada Lembaga Pendidikan Ganesha Operation Pekanbaru. Citra merek (brand image) merupakan representasi dari keseluruhan persepsi terhadap merek dan dibentuk dari informasi dan pengalaman masa lalu terhadap merek itu. Konsumen yang memiliki citra yang positif terhadap suatu merek, akan lebih memungkinkan untuk melakukan pembelian.

Dalam hal ini brand image Ganesha Operation Pekanbaru di masyarakat tergolong positif sehingga banyak orang suka dan memilih Ganesha Operation Pekanbaru sebagai tempat bimbingan belajar. Siswa memilih Ganesha Operation Pekanbaru di karenakan berbagai pertimbangan seperti, kualitas instruktur yang baik, cara belajar yang menarik dan siswa merasa puas belajar di Ganesha Operation Pekanbaru. Dengan brand image Ganesha Operation Pekanbaru yang bagus tersebut dapat meningkatkan keputusan siswa untuk memilih bimbingan belajar di Ganesha Operation Pekanbaru.

Dari hasil koefisien korelasi (R) diperoleh sebesar 0.946 hal ini memberi arti bahwa antara variable Brand Image dan Keputusan pembelian terdapat hubungan yang sangat kuat, untuk melihat kontribusi variable Brand Image terhadap keputusan pembelian dapat digunakan Adjusted $\mathrm{R}$ Square yaitu 0,895 hal ini memberikan arti 
bahwa variasi keputusan pembelian $89,50 \%$ ditentukan oleh variable brand image, sedangkan sisanya sebesar $10,50 \%$ lagi ditentukan oleh variable lain diluar penelitian ini.

\section{SIMPULAN}

Berdasarkan hasil dari pembahasan dapat ditarik kesimpulan sebagai berikut: Berdasarkan uji parsial variable brand image sangat berpengaruh signifikan terhadap keputusan Memilih Bimbingan Belajar Pada Lembaga Pendidikan Ganesha Operation Pekanbaru. Kontribusi variabel brand image terhadap keputusan memilih bimbingan belajar pada Lembaga Pendidikan Ganesha Operation Pekanbaru,

Beberapa saran yang diberikan dengan Pengaruh Brand Image terhadap keputusan memilih bimbingan belajar pada Lembaga Pendidikan Ganesha Operation adalah sebagai berikut:

Bagi Lembaga Pendidikan Ganesha Operation Pekanbaru agar lebih menjaga dan meningkatkan Brand Image Pendidikan Ganesha Operation di masyarakat untuk mempengaruhi keputusan memilih bimbingan belajar.

\section{DAFTAR RUJUKAN}

Antoni \& Meyzi Herianyo. 2017. Pengaruh Brand Image dan Kepercayaan Merek Terhadap Minat Beli Konsumen Pada Produk Mobil Toyota Etios Valco (Studi Pada PT. Agung Automall Pekanbaru). Jurnal JOM Fisip. Vol.4. No.1. Hal 1 - 10

Aaaker, David. 1997. Manajemen Ekuitas Merek. Spektrum Mitra Utama. Jakarta.

Candra Hakim Arif Prasetya, Srikandi Kumadji, Edy Yulianto. 2014. Pengaruh Citra Merek, Kualitas Produk Terhadap Kepercayaan Serta Keputusan Pembelian (Survei Pada Pembeli Sepeda Motor Honda Vario Pada PT. Sumber Purnama Sakti di Kabupaten Gresik). Jurnal Administrasi Bisnis (JAB). Vol. 15.
No.2.

administrasibisnis.studentjournal.u b.ac.id.

Ghozali. Imam. 2013. Aplikasi Analisis Multivariate Dengan Program SPSS. Cetakan Ketujuh. Semarang. Badan Penerbit Universitas Diponegoro.

Kotler, Philip \& Garry Armstrong. 2014. Principle of Marketing. $15^{\text {th }}$ edition. New Jersey: Pearson Prentice Hall.

Prawira, Bayu, YASA, Ni Nyoman Kerti. Pengaruh Kualitas Produk, Citra Merek dan Persepsi Harga Terhadap Minat Beli Produk Smartphone Samsung di Kota Denpasar. E-Jurnal Manajemen Universitas Udayana. Vol.3. No.12. ISSN 2302-8912: https://ojs.unud.ac.id/index.php/ma najement/article/view/10019.

Sangadji. E.M, dan Sopiah. 2013. Prilaku Konsume, Pendekatan Praktis Disertai: Himpunan Jurnal Penelitian. Yogyakarta. Penerbit Andi.

Sagita, Fitria Engla, Indonesia. 2013. Pengaruh Barnad Image dan Harga Terhadap Keputusan Pembelian Ulang Produk Kentucky Fried Chicken (KFC) Di Cabang Bakso Grand Mall Oleh Mahasiswa Universitas Negeri Padang. Vol.2. No.2.

Sugiyono, 2013. Metode Penelitian Kuantitatif Kualitatif dan $R \& D$. Bandung: Alfabeta. Bandung

Sangadji, E. M., dan Sopiah. 2013. Prilaku Konsumen: Pendekatan Praktis Disertasi: Himpunan Jurnal Penelitian. Yogyakarta: Penerbit Andi.

Tjiptono, Fandy. 2011. Strategi Pemasaran Edisi 3. Yogyakarta. ANDI e.ISSN: $2541-4356$ 